\title{
Younger age as a bad prognostic factor in patients with carcinoma of the cervix
}

\author{
Jean F. Delaloye*a, Sandro Pampallona ${ }^{a}$, Philippe A. Coucke ${ }^{b}$, Pierre De Grandi ${ }^{a}$ \\ ${ }^{a}$ Département de Gynécologie et d'Obstétrique, Centre Hospitalier Universitaire Vaudois, 1011 Lausanne, Switzerland \\ ${ }^{\mathrm{b}}$ Service de Radio-Oncologie, Centre Hospitalier Universitaire Vaudois, 1011 Lausanne, Switzerland
}

Received 9 August 1995; revision received 4 October 1995; accepted 5 October 1995

\begin{abstract}
Objective: To verify the influence of age on the prognosis of cervix carcinoma. Study design: Five hundred and sixty eight patients treated for a FIGO stage IB-IVA with radical irradiation in the Centre Hospitalier Universitaire Vaudois of Lausanne were subdivided according to the following age categories: $\leq 45,46-60,61-69$ and $>70$ years. Taking the $46-60$ years age group as the reference, the hazard ratios (HR) of death and corresponding $95 \%$ confidence intervals ( $95 \% \mathrm{CI}$ ) were estimated by means of a Cox multivariate analysis. Results: The 5 -year survival rates were, respectively, $57 \%, 67 \%, 60 \%$ and $45 \%$. For the youngest women the risk of death was significantly increased $(\mathrm{HR}=2.00,95 \% \mathrm{CI}[1.32-3.00])$ and was even more accentuated in advanced stages. Conclusion: Age under 45 years is a bad prognostic factor in carcinoma of the cervix.
\end{abstract}

Keywords: Age; Overall survival; Cervix carcinoma

\section{Introduction}

Several authors have reported that invasive carcinoma of the cervix had a poorer prognosis in younger patients than in older ones [1-14]. Others found no effect of age [15-23]. The potential difference in survival experience depending on age may have implications on the therapeutic approach, which so far has not been differentiated. In this report, we analyse a consecutive series of patients who attended a major Swiss University Hospital.

\section{Patients and methods}

\subsection{Database}

From January 1971 to December 1992, 642 consecutive patients with primary FIGO stage IB-IV carcinoma of the cervix were treated in the Centre Hospitalier Universitaire Vaudois, Lausanne. Only 568 of them were considered for the current study. Of the 74

\footnotetext{
* Corresponding author, Tel.: +21 3143269; fax: +21 3143263
}

patients excluded, 20 did not receive radiation therapy, 31 had incomplete baseline data, and 23 were lost to follow-up. Patients characteristics are summarized in Table 1. Baseline evaluation for FIGO classification included pelvic examination under local or general anesthesia, cervical biopsies, cystoscopy, rectoscopy, chest X-ray, intravenous pyelogram or computerized tomography. Variables available on all patients were age, FIGO stage, histology, surgery, radiation therapy duration and decade of treatment. Age has been subdivided as follows: $\leq 45,46-60,61-69$ and $>70$ years. The median age is 60 years (range $20-90$ years).

\subsection{Surgery}

One hundred and seventy-four patients with stage IBIIA tumor underwent a radical hysterectomy with pelvic lymphadenectomy before radiation therapy.

\subsection{Radiation therapy}

Post-operative radiation therapy was decided because of positive margins, positive lymph nodes or vascular invasion. 
Table 1

Patients characteristics

\begin{tabular}{|c|c|c|c|c|c|}
\hline & \multicolumn{4}{|c|}{ Age (years) } & \multirow[t]{2}{*}{ Total } \\
\hline & $\leq 45$ & $46-60$ & $61-69$ & $\geq 70$ & \\
\hline \multicolumn{6}{|l|}{ Decade } \\
\hline $1971-1979$ & $61(25)$ & $75(30)$ & $62(25)$ & $51(20)$ & $249(44)$ \\
\hline $1980-1989$ & $39(17)$ & $63(28)$ & $64(28)$ & $62(27)$ & $228(40)$ \\
\hline $1990-1992$ & $21(23)$ & $27(30)$ & $19(21)$ & $24(26)$ & $91(16)$ \\
\hline \multicolumn{6}{|l|}{ FIGO stage } \\
\hline IB & $39(32)$ & $28(17)$ & $23(16)$ & $14(10)$ & $104(18)$ \\
\hline II & $60(50)$ & $70(43)$ & $61(42)$ & $62(45)$ & $253(45)$ \\
\hline III & $18(15)$ & $60(37)$ & $49(34)$ & $53(39)$ & $180(32)$ \\
\hline IV & $4(3)$ & $6(3)$ & $12(8)$ & $8(6)$ & $30(5)$ \\
\hline \multicolumn{6}{|l|}{ Histology } \\
\hline Squamous cell & $104(86)$ & $142(87)$ & $129(90)$ & $119(88)$ & $494(88)$ \\
\hline Other & $17(14)$ & $21(13)$ & $15(10)$ & $17(12)$ & $70(12)$ \\
\hline \multicolumn{6}{|l|}{ Surgery } \\
\hline Yes & $63(52)$ & $55(33)$ & $35(24)$ & $21(15)$ & $174(31)$ \\
\hline No & $58(48)$ & $110(67)$ & $110(76)$ & $116(85)$ & $394(69)$ \\
\hline \multicolumn{6}{|c|}{ Therapy duration } \\
\hline$<58$ days & $95(79)$ & $121(73)$ & $110(76)$ & $97(71)$ & $423(74)$ \\
\hline$\geq 58$ days & $26(21)$ & $44(27)$ & $35(24)$ & $40(29)$ & $145(26)$ \\
\hline
\end{tabular}

Number in parentheses is percentage of column

External radiation therapy was delivered initially with a betatron and in subsequent years with a linear accelerator. The pelvic volume was approached using a four-field box technique tailored in function of local extent of the tumor. The dose per fraction generally was 180-200 cGy/fraction, 5 days per week. Reference point was ICRU point. Patients with stage IB-IIA received 45 Gy to the whole pelvis. Patients with non-operable stage IIB-IIIB received 45 Gy to the whole pelvis and a $10-15$ Gy boost to one or both parameters.

Intracavitary curietherapy delivered a boost of $30 \mathrm{~Gy}$ to point $A$ or 45 Gy to the vaginal cuff (when a hysterectomy was performed), using an intra-uterine probe or a vaginal ovoid. The rectal dose was measured during the insertion of the source and the total rectal dose for the whole period of brachytherapy was computed. In the first decade (1971-79), low dose-rate curietherapy (LDR) was systematically used, whereas from the second decade on all patients were submitted to high doserate (HDR). The isotope used for LDR was radium, and the isotope used for HDR was cesium.

External radiation therapy and intracavitary curietherapy were performed concomitantly (Con) or sequentially (Seq). Sequential curietherapy was given at weekly intervals, 5-20 days following completion of external radiation. From 1990 to 1993, radiation therapy was Seq in $94 \%$ of the patients. This distribution is less homogeneous for decades 1970-79 (2\%) and 1980-89 $(36 \%)$.

\subsection{Radiation therapy duration}

This included the duration of external radiation therapy, the time interval between the former and brachytherapy, and the duration of brachytherapy. Therapy duration was calculated in days. Median therapy duration was $\mathbf{4 4}$ days. For the purpose of the analysis, patients were classified according to whether they had rather long therapies, taking 58 days (the 75 th percentile) as an arbitrary cut-off. It is generally recognized that radiation therapy given over extended time interval is associated with reduced survival. [24-26].

\subsection{Statistical methods}

The primary endpoint of this study was overall survival (OS), which was defined as time from beginning of radiation therapy to death due to any cause. Survival status for all patients was updated during Summer of 1993.

Statistical analyses were carried out by means of the software package Stata [27]. Survival percentages over time have been calculated by the Kaplan-Meier method [28] and their corresponding standard errors (S.E.) with Greenwood's formula [29]. For univariate analysis of OS the $P$-values from the log-rank test are reported for each comparison considered [30]. Estimated hazard ratios (HR) of death, with respect to the indicated reference group, their $95 \%$ confidence intervals $(95 \% \mathrm{Cl})$ and 
$P$-values were calculated with multivariate proportional-hazard-regression-model [31]. The following variables, coded into binary indicators to reflect the same subgroups shown in the tables, were included in the multivariate analysis: FIGO stage, histology, surgery, duration of therapy and decade of treatment. Values of HR greater than unity indicate increased rates of death with respect to the chosen reference category. For analyses other than on OS, chi-squared tests for independence have been used [32]. All probability values were for twosided tests.

For the purpose of the analyses of survival, observations have been censored at 5 years in order to limit the effect of competing causes of mortality (cause of death was not known with certainty) and also to avoid having only patients registered during the earlier periods contribute to the right tail of the survival curves. Five-year survival was considered a relevant endpoint for cervical cancer patients.

\section{Results}

As concerns the distribution of various characteristics according to age, we have observed a higher percentage of stage IB patients in the age group under 45 , and a decreasing percentage of women having undergone surgery with increasing age. On the other hand, the frequency of histologic subtypes and of radiation therapy duration was consistent across age groups. Age distribution did not vary across decades.

A total of 71 patients developed pelvic recurrence and a total of 101 patients developed distant metastasis. In 27 women both events have been observed. The 5-year survival rates were, respectively, $57 \pm 5 \%$ for the $\leq 45$ year group, $67 \pm 5 \%$ for the 46-60-year group, $60 \pm 4 \%$ for the $61-69$-year group, and $45 \pm 5 \%$ for the $\geq 70$-year group.

An analysis based on the Cox model including only age has been used to estimate the HRs for each age group and the results are reported in Table 2. A similar analysis has been performed for each of the other available variables and only stage was shown to be a statistically significant predictor of survival, more advanced stages being at higher risk of death. Age being the factor of primary interest, a multivariate analysis has

Table 2

Univariate analysis of effect of age: hazard ratios (HR) and related $95 \%$ confidence intervals $(95 \% \mathrm{CI})$

\begin{tabular}{llll}
\hline $\begin{array}{l}\text { Age } \\
\text { (years) }\end{array}$ & HR & $95 \% \mathrm{CI}$ & $P$-value \\
\hline $\mathbf{5 4 5}$ & 1.39 & $0.93-2.08$ & 0.105 \\
$\mathbf{4 6 - 6 0}$ & Reference & group & \\
$61-69$ & 1.28 & $0.86-1.89$ & 0.219 \\
$\geq 70$ & 1.77 & $1.21-2.58$ & 0.003 \\
\hline
\end{tabular}

Tabie 3

Multivariate analysis of effect of age: hazard ratios (HR) and related $95 \%$ confidence intervals $(95 \% \mathrm{CI})$

\begin{tabular}{llll}
\hline $\begin{array}{l}\text { Age } \\
\text { (years) }\end{array}$ & HR & $95 \%$ CI & $P$-value \\
\hline$\leq 45$ & 2.00 & $1.32-3.01$ & $<0.001$ \\
$46-60$ & Reference & group & \\
$61-69$ & 1.22 & $0.82-1.80$ & 0.332 \\
$\geq 70$ & 1.62 & $1.11-2.36$ & 0.13 \\
\hline
\end{tabular}

See the statistical method section for the variables included in the Cox model. Only results concerning age are displayed.

been performed in order to assess its role allowing for the potential confounding effect of the other covariates. The results are displayed in Table 3 only for age and suggest a U-shaped relationship between increasing age and risk of death. In particular, women aged 45 years or less were exposed to the highest risk of death, namely the double of the risk of the 46-60 years group $(\mathrm{HR}=2.00,95 \% \mathrm{CI}[1.32-3.01])$. After 60 years, the risk of death increased with increasing age, but never reached the level observed in the youngest group. The role of stage was also confirmed by the multivariate analysis.

We have investigated whether the effect of age was constant within each group of women determined by the stage of the disease. An exploratory multivariate regression has been performed within each stage subgroup in order to compare the survival of women aged 45 or less to all other. The results are reported in Table 4. Younger women were always at a higher risk of death than older women, but their risk increased with increasing stage. In the subgroup of stage III, women aged 45 or less had a more than double risk of death $(\mathrm{HR}=2.28,95 \% \mathrm{CI}$ [1.26-4.11]) than older women. Similarly, in the subgroup of stage IV there was an indication of a five-fold increase in the risk of death for younger women $(\mathrm{HR}=5.15,95 \% \mathrm{CI}[1.21-21.9])$. These results have to be interpreted with caution due to their exploratory

Table 4

Influence of age: multivariate analysis stratified by FIGO stage

\begin{tabular}{|c|c|c|c|c|}
\hline $\begin{array}{l}\text { FIGO } \\
\text { stage }\end{array}$ & $\begin{array}{l}\text { Age } \\
\text { (years) }\end{array}$ & HR & $95 \% \mathrm{CI}$ & $P$-value \\
\hline \multirow[t]{2}{*}{ I } & $\leq 45$ & 1.81 & $0.62-5.24$ & 0.276 \\
\hline & $>45$ & \multicolumn{3}{|c|}{ Reference group } \\
\hline \multirow[t]{2}{*}{ II } & $\leq 45$ & 1.45 & $0.86-2.43$ & 0.159 \\
\hline & $>45$ & \multicolumn{3}{|c|}{ Reference group } \\
\hline \multirow[t]{2}{*}{ III } & $\leq 45$ & 2.28 & $1.26-4.11$ & 0.006 \\
\hline & $>45$ & \multicolumn{3}{|c|}{ Reference group } \\
\hline \multirow[t]{2}{*}{ IV } & $\leq 45$ & 5.15 & $1.21-21.9$ & 0.027 \\
\hline & $>45$ & \multicolumn{3}{|c|}{ Reference group } \\
\hline
\end{tabular}

See the statistical methods section for the variables included in the Cox model. Only results concerning age are displayed. 
nature and to the small size of the groups, particularly so for stage IV.

\section{Discussion}

Some authors have reported a positive association between age and risk of death, which could not just be attributed to the obvious shorter life expectancy of the elderly [1]. More often, however, a higher risk for younger women has been observed $[1,3,6,13,14]$. Additionally, it has been noted that younger patients with early-stage disease survived longer than older patients. but this tendency was reversed when the disease was advanced [13]. Evidence from other studies does not consistently point towards an association between age and risk of death. [15,23,33,34].

Our results suggest that younger women are at increased risk of death. The observation that this risk increases when the disease is diagnosed at an advanced stage may imply that the disease is more aggressive in younger women. In this study, we do not have available reliable classification of cause of death and, therefore. we cannot assess whether younger women differ from older women in this respect. We cannot exclude either that our results are biased by the retrospective nature of the study and that our observations could be attributable to some confounders that we have not allowed for. The age-specific mortality rate of the cervix carcinoma for younger women cannot be attributed to a new papilloma virus epidemic during the last 20 years. since Sebbelov et al. have shown that the proportion of HPV positive patients is equal in all age groups [35]. Moreover, this age-specific mortality rate cannot be accounted for by difference in intrinsic radiosensitivity [36]. Apoptosis and/or Bcl-2 expression, p53 mutations, IL-6 autocrine production, and ploidy should be investigated to determine the reasons of treatment resistance [37-43]. The ongoing research on potential doubling time (Tpot) in cervical cancer may shed some light on this issue [44]. The knowledge of all these cellular and molecular mechanisms could potentially lead to the elaboration of new strategies for therapeutic approaches.

\section{References}

[1] Lindell A. Carcinoma of the uterine cervix: Incidence and influence of age. A statistical study. Acta Radiol 1952; 92 (Suppl): $1-102$.

[2] Kottmeier HL. Surgical and radiation treatment of carcinoma fo the uterine cervix. Acta Obstet Gynecol Scand 1964; 43 (Suppl 2): 1-49.

[3] Stanhope CR, Smith JP, Wharton JT, Rutledge FN, Fletcher GH, Gallagher HS. Carcinoma of the cervix. The effect of agc on survival. Gynecol Oncol 1980; 10: 188193.

[4] Gynning I, Johnsson JE, Alm P, Tropé C. Age and prognosis in stage Ib squamous cell carcinoma of the cervix. Gynecol Oncol 1982; $15: 18-26$.
[5] Prempree T, Patanaphan V, Sewshand W, Scott RM. The influence of patients' age and tumor grade on the prognosis of carcinoma of the cervix. Cancer 1983; 51: 1764-1771.

[6] Lybeert MLM. Meerwaldt JH, van Putten WLJ. Age as a prognostic factor in carcinoma of the cervix. Radiother Oncol 1987; 9: $147-151$

17] Elliott PM, Tattersall MHN, Coppleson M, Russell P, Coates AS, Solomon HJ. Changing character of cervical cancer in young women [letter]. Br Med J 1989; 298: 288.

[8] Dattoli MJ, Gretz HF, Beller Z et al. Analysis of multiple prognostic factors in patients with stage IB cervical cancer: Age as a major determinant. Int J Radiat Oncol Biol Phys 1989; 17 : $41-47$.

[9] Lee $Y N$, Wang KL, Lin MH et al. Radical hysterectomy with pelvic lymph node dissection for treatment of cervical cancer. A clinical review of 954 cases. Gynecol Oncol 1989; 32: 135-142.

[10] Maddux HR, Varia MA, Spann CO, Fowler WC, Rosenman JG. Invasive carcinoma of the uterine cervix in women of age 25 or less. Int J Radiat Oncol Biol Phys 1990; 19: 701-706

[11] Clark MA, Naahas W, Markert RJ, Dodson MG. Cervical cancer: Women aged 35 and younger compared to women aged 36 and older. Am J Clin Oncol 1991; 14: 352-356.

121 Kodama S. Kanasawa K., Honna S, Tanaka K. Age as a prognostic factor in patients with squamous cell carcinoma of the uterine cervix. Cancer, 1991; 68: 2481-2485.

[13] Rutledge FN, Mitchell MF, Munsell M, Bass S, Mc Guffee V. Atkins EN. Youth as a prognostic factor in carcinoma of the cervix: a matched analysis. Gynecol Oncol 1992; 44: 123-130.

[14] Robertson D, Fedorkow DM, Stuart GCE, Mc Gregor SE. Age as a prognostic variable in cervical squamous cell carcinoma Eur J Gynaecol Oncol 1993; 14: 283-291.

[15] Dodds JR. Latour JP. Relationship of age to survival rate in carcinoma of the cervix. Am J Obstet Gynecol 1961; 82:33-36.

[16] Decker DG. Fricke RE, Pratt JH. Invasive carcinoma of the cervix in young women. JAMA 1955; 158: 1417-1420

[17] Kyriakos M, Kempson RL, Perez CA. Carcinoma of the cervix in young women. Obstet Gynecol 1971; 38: 930-944.

[18] Kjorstad KE. Carcinoma of the cervix in the young patient. Obstet Gynecol 1977; 50: 28-30.

[19] Baltzer I. Koepcke W. Lohe KJ, Ober KG, Zander J. Age and 5 -year survival rates in patients with operated carcinoma of the cervix. Gynecol Oncol 1982; 14: 220-224.

[20] Carmichael JA, Clark DH, Moher D, Ohlke ID, Karchmar EJ. Cervical carcinoma in women aged 34 and younger. Am J Obstet Gynecol 1986; 154: 264-269.

[21] Meanwell CA, Kelly KA, Wilson $S$ et al. Young age as a prognostic factor in cervical cancer. Analysis of population based data from 10022 cases. Br Med J 1988; 296: 386-391.

[22] Spanos WK, King A, Keeney E, Wagner R, Slater JM. Age as a prognostic factor in carcinoma of the cervix. Gynecol Oncol 1989; 35: 66-68.

[23] Juner EJ, Symonds RP, Whatson ER, Lamont DW. Survival of younger cervical carcinoma patients treated by radical radiotherapy in the West of Scotland 1964-1984. Br J Obstet Gynecol 1989; 96: 522-528.

[24] Fyles A. Keane TJ, Barton MB, Simm J. The effect of treatment duration in the local control of cervix cancer. Radiother Oncol 1992: $25: 273-279$

[25] Lanciano RM, Pajak TF, Martz K, Hanks GE. The influence of treatment time on outcome for squamous cell cancer of the uterine cervix treated with radiation: A patterns-of-care study. Int J Radiat Oncol Biol Phys 1993; 25: 391--397.

[26] Girinsky T. Rey A, Roche B et al. Overall treatment time in advanced cervical carcinomas: A critical parameter in treatment outcome Int. J Radiat. Oncol. Biol. Phys. 1993, 27, 1051-1056.

[27] Stata. Computing Resource Center Reference Manual, 1991

[28] Kaplan EL. Meier P. Nonparametric estimation from incomplete observations. I Am Stat Assoc 1958; 53:457-481. 
[29] Greenwood M. Reports on public health and medical subjects: The natural duration of cancer. HMSO 1926; 33: 1-16.

[30] Peto R, Pike M.C, Armitage P et al. Design and analysis of randomized clinical trials requiring prolonged observation of each patient. II. Analysis and examples. Br J Cancer 1977; 35: 1-39.

[31] Cox DR. Regression models and life tables. J R Stat Soc B 1972; 34: $187-220$.

[32] Armitage P, Berry G. Statistical methods in medical research (2nd. ed.). Oxford: Blackwell, 1987.

[33] Stellato G, Tikkala L, Kajanoja P. Invasive cervical carcinoma in patients ages 35 or younger. Eur J Gynaecol Oncol 1992; 13: 490-493.

[34] Cancer incidence in five continents. IARC Scientific Publications 1992; 120: 25-30.

[35] Sebbelov AM, Kjorstad KE, Abeler VM. Norrild B. The prevalence of human papillomavirus type 16 and 18 DNA in cervical cancer in different age groups: A study on the incidental cases of cervical cancer in Norway in 1983. Gynecol Oncol 1991; 41: 141-148.

[36] West CML, Davidson SE, Burt PA, Hunter RD. The intrinsic radiosensitivity of cervical carcinoma: correlation with clinical data. Int J Radiat Oncol Biol Phys 1995; 31: 841.
[37] Kerr JFR, Winterford CM., Harmon BV. Apoptosis. Its significance in cancer and cancer therapy. Cancer 1994; 73: 2013.

[38] Levine EL, Davidson SE, Roberts SA, Chadwick CA, Potten CS, West CML. Apoptosis as predictor of response to radiotherapy in cervical carcinoma. Lancet 1994; 344: 472.

[39] Steck KD, McDonnell TJ, El-Naggar AK. Flow cytometric analysis of apoptosis and BCL-2 in human solid neoplasms. Cytometry 1995; 20: 154-161.

[40] Chen M, Quintans J, Thompson C, Kufe DW, Weichselbaum RR. Suppression of Bcl-2 messenger RNA production may mediate apoptosis after after ionizing radiation, tumor necrosis factor a, and ceramide. Cancer Research 1995; 55: 991-994.

[41] Lowe SW, Bodis S, McClatchey A et al. p53 status and the efficacy of cancer therapy in vivo. Science 1994; 266: 807-810.

[42] Eustace D, Han X, Rowbottom A, Riches P, Heyderman E. Interleukin-6 (IL-6) function as an autocrine growth factor in cervical carcinomas in vitro. Gynecol Oncol 1993; 50: 15-19.

[43] Konski A, Domenico D, Irwing D et al. Flow cytometric DNA content analysis of paraffin-embedded tissue derived from cervical carcinoma. Int J Radiat Oncol Biol Phys 1994; 30: 839-843.

[44] Withers HR. Treatment induced accelerated human tumorgrowth. Semin Radiat Oncol 1993; 3: 135-141. 